\title{
Neural Networks Analysis of Airfield Pavement Heavy Weight Deflectometer Data
}

\author{
Kasthurirangan Gopalakrishnan*
}

Department of Civil, Construction and Environmental Engineering, Iowa State University, Ames, Iowa, USA

\begin{abstract}
The Heavy Weight Deflectometer (HWD) test is one of the most widely used tests for assessing the structural integrity of airport pavements in a non-destructive manner. The elastic moduli of the individual pavement layers predicted from the HWD deflection measurements through inverse engineering analysis are effective indicators of pavement layer condition. The primary objective of this study was to develop a tool for backcalculating non-linear pavement layer moduli from HWD data using Artificial Neural Networks (ANN) for rapid structural evaluation of airfield pavements. A multilayer, feed-forward backpropagation ANN which uses an error-backpropagation algorithm was trained to approximate the HWD backcalculation function. The synthetic database generated using an axisymmetric pavement finite-element program was used to train the ANN. Using the ANN, the Asphalt Concrete (AC) moduli and subgrade moduli were successfully predicted. Apart from the moduli, an attempt was made to predict the critical pavement structural responses using ANN models. The final product was used in backcalculating pavement layer moduli and predicting subgrade deviator stresses from actual field data acquired at the Federal Aviation Administration's National Airport Pavement Test Facility (NAPTF).
\end{abstract}

\section{INTRODUCTION}

The Falling Weight Deflectometer (FWD) test is one of the most widely used tests for assessing the structural integrity of roads in a non-destructive manner. In the case of airfields, a Heavy Weight Deflectometer (HWD) test, which is similar to a FWD test, but using higher load levels, is used. In an FWD/HWD test, an impulse load is applied to the pavement surface by dropping a weight onto a circular metal plate and the resultant pavement surface deflections are measured directly beneath the plate and at several radial offsets. The deflection of a pavement represents an overall "system response" of the pavement layers to an applied load. A conventional Asphalt Concrete (AC) pavement is typically made up of three layers: a surface layer paved with AC mix, a base or/and subbase layer made up of crushed stone, and a subgrade layer made up of natural soil. When a wheel load is applied on an AC pavement, the pavement layers deflect nearly vertically to form a basin. The FWD/HWD test tries to replicate the force history and deflection magnitudes of a moving truck tire/aircraft tire.

The deflected shape of the basin is predominantly a function of the thickness of the pavement layers, the moduli of individual layers, and the magnitude of the load. "Backcalculation" is the accepted term used to identify a process whereby the elastic (Young's) moduli of individual pavement layers are estimated based upon measured FWD/HWD surface deflections. As there are no closed-form solutions to accomplish this task, a mathematical model of the pavement system (called a forward model) is constructed and used to compute theoretical surface deflections with assumed initial layer moduli values at the appropriate

\footnotetext{
*Address correspondence to this author at the Department of Civil, Construction, and Environmental Engineering, 354 Town Engineering Building, Iowa State University, Ames, IA 50011, USA; Tel: 1-515-2943044; Fax: 1-515-294-8216;

E-mail: rangan@iastate.edu,rangan108@gmail.com
}

FWD/HWD loads. Through a series of iterations, the layer moduli are changed, and the calculated deflections are then compared to the measured deflections until a match is obtained within tolerance limits. Most of the commercial backcalculation programs currently in use (e.g. WESDEF, BISDEF) utilize an Elastic Layer Program (ELP) as the forward model to compute the surface deflections. For example, WESDEF uses WESLEA and BISDEF uses BISAR.

The ELPs consider the pavement as an elastic multilayered media, and assume that pavement materials are linear-elastic, homogeneous and isotropic. However, in reality, it has been found that certain pavement materials do not show linear stress-strain relation under cyclic loading. The non-linearity or stress-dependency of resilient modulus for unbound granular materials and cohesive fine-grained subgrade soils is well documented in literature $[1,2]$. Unbound granular materials used in the base/subbase layer of an AC pavement show "stress-hardening" behavior (increase in resilient modulus with increasing hydrostatic stress) and cohesive subgrade soils show "stress-softening" behavior (reduction in resilient moduli with increased deviator stress). Therefore, the layer modulus is no longer a constant value, but a function of the stress state. Also, the ELPs do not account for the available shear strength of these unbound materials and frequently predict tensile stresses at the bottom of unbound granular layers which exceeds the available strength. Thus, the pavement layer moduli values predicted using ELP-based backcalculation programs are not very realistic.

ILLI-PAVE is a two-dimensional axi-symmetric pavement finite-element (FE) software developed at the University of Illinois at Urbana-Champaign [3]. It incorporates stress-sensitive material models and it provides a more realistic representation of the pavement structure and its response to loading. The primary objective of this study was to develop a tool for backcalculating non-linear pavement 
layer moduli from FWD/HWD data using Artificial Neural Networks (ANN). The reason for using ANN to accomplish this task is that once trained, they offer mathematical solutions that can be easily calculated in real-time on even the basic personal computers, unlike conventional backcalculation programs. Also, ANN can learn a backcalculation function that is based on much more realistic models of pavement response (e.g., ILLI-PAVE) than are used in traditional-basin matching programs.

ANNs have been successfully used in the past for the backcalculation of flexible pavement moduli from FWD data [4]. However, they did not account for realistic pavement layer properties as ELP-generated synthetic database was used to train the ANN. Therefore, ILLI-PAVE was used in this study to develop the synthetic database which accounts for the nonlinearity in unbound material behavior. A multilayer, feed-forward network which uses an error-backpropagation algorithm (LMS minimization) was trained to approximate the HWD backcalculation function. The final product was used in backcalculating pavement layer moduli from actual field data acquired at the National Airport Pavement Test Facility (NAPTF). The NAPTF was constructed to generate full-scale testing data to support the investigation of the performance of airport pavements subjected to new generation aircrafts. The results from this study were compared with those obtained using a traditional ELP-based backcalculation program. It is noted that this is a preliminary study specifically targeted towards the backcalculation of pavement layer moduli from HWD data acquired at the NAPTF.

Recent research studies at the Iowa State University and University of Illinois have focused on the development of ANN based flexible pavement analysis models to predict critical pavement responses and layer moduli [5]. Researchers have successfully demonstrated the use of ANNs trained with ILLI-PAVE results as pavement structural analysis tools for the rapid and accurate prediction of critical responses and deflection profiles of flexible pavements subjected to typical highway loadings [5]. The current study described in this paper focused on the development of ANNbased models for the rapid non-destructive evaluation of airport flexible pavements subjected to new-generation, heavy aircrafts such as Boeing B-777.

\section{DATABASE GENERATION FOR ANN TRAINING AND TESTING}

A conventional airport flexible pavement section was modeled as a five-layered (AC layer, base layer, subbase layer, subgrade layer and a sand layer as constructed in conventional NAPTF test sections), two-dimensional, axisymmetric FE structure. A typical HWD test is performed by dropping a 36,000-lb load on the top of circular plate with a radius of 6 inches resting on the surface of the pavement. The loading duration is about $30 \mathrm{~ms}$. Deflections are typically measured at offsets of 0-,12-,24-,36-,48- and 60inches from the center of loading plate. The effect of HWD loading was simulated in ILLI-PAVE.

The AC layer and the sand layer were treated as linear elastic material. Stress-dependent elastic models along with Mohr-Coulomb failure criteria were applied for the base, subbase and subgrade layers. The 'stress-hardening' K- $\theta$ model was used for the base and subbase layers:

$$
M_{R}=\frac{\sigma_{D}}{\varepsilon_{R}}=K \theta^{n}
$$

where $M_{R}$ is resilient modulus (psi), $\theta$ is bulk stress (psi) and $\mathrm{K}$ and $\mathrm{n}$ are statistical parameters. The following relationship exists between $\mathrm{K}$ and $\mathrm{n}\left(\mathrm{R}^{2}=0.68, \mathrm{SEE}=0.22\right)[6]$ :

$$
\log _{10}(K)=4.657-1.807 n
$$

The 'stress-softening' bilinear model was used for the subgrade layer:

$\begin{array}{ll}M_{R}=M_{R i}+K_{1} \cdot\left(\sigma_{d}-\sigma_{d i}\right) & \text { for } \sigma_{d}<\sigma_{d i} \\ M_{R}=M_{R i}+K_{2} \cdot\left(\sigma_{d}-\sigma_{d i}\right) & \text { for } \sigma_{d}>\sigma_{d i}\end{array}$

where $M_{R}$ is resilient modulus (psi), $\sigma_{d}$ is applied deviator stress (psi), and $\mathrm{K}_{1}$ and $\mathrm{K}_{2}$ are statistically determined coefficients from laboratory tests.

The thickness of the AC, base, subbase, subgrade and sand layers were held at constant values of 5, 8, 12, 95, and 120 inches respectively. These layer thicknesses are for a conventional AC pavement section (referred to as "MFC") constructed at the NAPTF. The elastic modulus of the sand layer was fixed at 45,000 psi. Pavement surface deflections were computed at spacings of $0\left(D_{0}\right), 12\left(D_{12}\right), 24\left(D_{24}\right), 36$ $\left(\mathrm{D}_{36}\right), 48\left(\mathrm{D}_{48}\right)$, and $60\left(\mathrm{D}_{60}\right)$ inches from the load center. Apart from the deflection basins, the strains at the bottom of the AC layer $\left(\varepsilon_{\mathrm{AC}}\right)$ and on top of the subgrade $\left(\varepsilon_{\mathrm{SG}}\right)$, major and minor stresses $\left(\sigma_{1}\right.$ and $\left.\sigma_{3}\right)$ and deviatoric stress on top of subgrade $\left(\sigma_{\mathrm{D}}\right)$ were also computed. The importance of these parameters in the context of airport flexible pavement design is discussed later.

Deflection Basin Parameters (DBPs) derived from FWD/HWD deflection measurements are shown to be good indicators of selected pavement properties and conditions [7]. Recently, DBPs were used in developing new relationships between selected pavement layer condition indicators and FWD deflections by applying regression and ANN techniques [8]. The DBPs considered in this study are shown in Table 1. Each DBP supposedly represents the condition of specific pavement layers. For example, AUPP is sensitive to the $\mathrm{AC}$ layer properties whereas $\mathrm{BCI}$ and $\mathrm{AI}_{4}$ are expected to reflect the condition of subgrade. Some of these DBPs were included as inputs for training the ANN apart from the 6 independent deflection measurements $\left(D_{0}\right.$ to $\left.D_{60}\right)$.

A total of 5,000 data sets were generated by varying the $\mathrm{AC}$ and subgrade layer moduli, the ' $\mathrm{K}_{\mathrm{b}}$ '- ' $\mathrm{n}_{\mathrm{b}}$ ' and ' $\mathrm{K}_{\mathrm{s}}$ ' - ' $\mathrm{n}_{\mathrm{s}}$ ' values (note that $\mathrm{K}$ and $\mathrm{n}$ are related) for the base and subbase layers respectively. Of the total number of data sets, 3,750 data vectors were used in training the ANN and the rest 1,250 data vectors were utilized for the testing the network after the training was completed. The ranges of layer properties used in training the ANN are summarized in Table 2.

In order for the network weights to compare the features to one another more easily, it is generally desirable to reduce each feature in the data set to zero mean and an approximately equal variance, usually unity. But, in this case, as 
the data was well controlled, all the features were reduced to similar orders of magnitude. Also, it is crucial that the training and test data both represent sampling from the same statistical distribution, which is also taken care of in this study.

Table 1. Deflection Basin Parameters (DBPs) Used in this Study

\begin{tabular}{|c|c|}
\hline $\begin{array}{c}\text { Deflection Basin Parameter } \\
\text { (DBP) }\end{array}$ & Formula \\
\hline \hline AREA & AREA $=6\left(\mathrm{D}_{0}+2 \mathrm{D}_{12}+2 \mathrm{D}_{24}+\mathrm{D}_{36}\right) / \mathrm{D}_{0}$ \\
\hline $\begin{array}{c}\text { Area Under Pavement } \\
\text { Profile (AUPP) }\end{array}$ & $\mathrm{AUPP}=\left(5 \mathrm{D}_{0}-2 \mathrm{D}_{12}-2 \mathrm{D}_{24}-\mathrm{D}_{36}\right) / 2$ \\
\hline Area Index & $\mathrm{AI}_{4}=\left(\mathrm{D}_{36}+\mathrm{D}_{48}\right) / 2 \mathrm{D}_{0}$ \\
\hline Base Curvature Index (BCI) & $\mathrm{BCI}=\mathrm{D}_{24}-\mathrm{D}_{36} \mathrm{BCI} 2=\mathrm{D}_{60}-\mathrm{D}_{48}$ \\
\hline Base Damage Index (BDI) & $\mathrm{BDI}=\mathrm{D}_{12}-\mathrm{D}_{24}$ \\
\hline Deflection Ratio & $\mathrm{DR}=\mathrm{D}_{12} / \mathrm{D}_{0}$ \\
\hline Shape Factors & $\mathrm{F}_{1}=\left(\mathrm{D}_{0}-\mathrm{D}_{24}\right) / \mathrm{D}_{12} \mathrm{~F}_{2}=\left(\mathrm{D}_{12}-\mathrm{D}_{36}\right) / \mathrm{D}_{24}$ \\
\hline
\end{tabular}

\section{NETWORK ARCHITECTURE}

A generalized n-layer feedforward artificial neural network which uses an error-backpropogation algorithm [9] was implemented in the Visual Basic (VB 6.0) programming language. The program can allow for a general number of inputs, hidden layers, hidden layer elements, and output layer elements. Two hidden layers were found to be sufficient in solving a problem of this size and therefore the architecture was reduced to a four-layer feedforward network. A four-layer feedforward network consists of a set of sensory units (source nodes) that constitute the input layer, two hidden layer of computation nodes, and an output layer of computation nodes. The following notation is generally used to refer to a particular type of architecture that has two hidden layers: (\# inputs)-(\# hidden neurons)-(\# hidden neurons)-(\# outputs). For example, the notation 10-40-40-3 refers to an ANN architecture that takes in 10 inputs (features), has 2 hidden layers consisting of 40 neurons each, and produces 3 outputs.

An ANN-based backcalculation procedure was developed to approximate the FWD/HWD backcalculation function. Using the ILLI-PAVE synthetic database, the ANN was trained to learn the relation between the synthetic deflection basins (inputs) and the pavement layer moduli (outputs).

To track the performance of the network a Root Mean Squared Error (RMSE) at the end of each epoch was calculated. An epoch is defined as one full presentation of all the training vectors to the network. The RMSE at the end of each epoch defined as:

$R M S E=\sqrt{\frac{\sum_{j=1}^{N}\left[d_{j}-Y\left(X_{j}\right)\right]}{N}}$

Where $d_{j}$ is the desired response for the input training vector $X_{j}$, and $N$ is the total number of input vectors presented to the network for training. In order for the network to 'learn' the problem smoothly, a monotonic decrease in the RMSE is expected with increase in the number of epochs.

Separate ANN models were used for each desired output rather than using the same architecture to determine all the outputs together. The most effective set of input features for each ANN model were determined based on both engineering judgment and the experience gained through past research studies conducted at the University of Illinois. Parametric analyses were performed by systematically varying the choice and number of inputs and number of hidden neurons to identify the best-performance networks. As it was found that the prediction accuracy of the network remained the same for hidden layers greater than or equal to two, the number of hidden layers was fixed at two for all runs. The learning curve (RMSE Vs number of epochs) and the testing RMSE were studied in order to arrive at the best networks.

A range of $(-0.2,+0.2)$ was used for random initialization of all synaptic weight vectors in the network. The presence of a nonlinear activation function, $\varphi($.$) in the hidden layer(s)$ is important because, otherwise, the input-output relation of the network could be reduced to that of a single-layer perceptron. The computation of the $\delta$ (local gradient) for each neuron of the multilayer perceptron requires that the function $\varphi($.$) be continuous. For this problem, an asymmetric$ hyperbolic tangent function (tanh) was chosen as the nonlinear activation function at the output end of all hidden neurons. Since, the final outputs (layer moduli) are real values rather than binary outputs, a linear combiner model

Table 2. Ranges of Layer Properties Used to Train the ANN

\begin{tabular}{|c|c|c|c|}
\hline Pavement Layer & Thickness (in.) & Elastic Layer Modulus (ksi) & Poisson's Ratio \\
\hline \hline Asphalt Concrete & 5 & $100-2,000$ & 0.35 \\
\hline Base & 8 & $\mathrm{~K}_{\mathrm{b}}: 1.6-20 \mathrm{n}_{\mathrm{b}}: 0.2-0.8$ & 0.35 \\
\hline Subbase & 12 & $\mathrm{~K}_{\mathrm{s}}: 1.6-20 \mathrm{n}_{\mathrm{s}}: 0.2-0.8$ & 0.35 \\
\hline Subgrade & 95 & $1.6-20$ & 0.45 \\
\hline Sand & 120 & 45 & 0.4 \\
\hline
\end{tabular}


was used for neurons in the output layer, thus omitting the nonlinear activation function. A smooth learning curve was achieved with a learning-rate parameter of 0.001 .

A Summary of the sensitivity analyses performed to select the best-performance networks for predicting AC modulus $\left(\mathrm{E}_{\mathrm{AC}}\right)$ and subgrade modulus $\left(\mathrm{E}_{\mathrm{Ri}}\right)$ in MFC section are shown in Table 3. Similarly, the best-performance networks for predicting $\mathrm{n}_{\mathrm{b}}$ and $\mathrm{n}_{\mathrm{s}}$ in MFC section are highlighted in Table 4. The base and subbase layer moduli were the hardest to predict. The difficulty associated with

Table 3. Summary of Sensitivity Analyses for Predicting AC and Subgrade Moduli

\begin{tabular}{|c|c|c|c|c|c|c|}
\hline \multirow[t]{2}{*}{ Trial } & \multirow{2}{*}{ Input } & \multirow{2}{*}{ Output } & \multirow{2}{*}{ Network Architecture } & \multirow{2}{*}{ No. of Epochs } & \multicolumn{2}{|c|}{ Testing RMSE } \\
\hline & & & & & $\mathbf{E}_{\mathrm{AC}}(\mathbf{k s i})$ & $\mathbf{E}_{\mathbf{R i}}(\mathbf{k s i})$ \\
\hline 2 & $\mathrm{D}_{0} \sim \mathrm{D}_{72}$ & $\mathrm{E}_{\mathrm{AC}}, \mathrm{E}_{\mathrm{Ri}}$ & $7-40-40-2$ & 10,000 & 96 & 1.7 \\
\hline 3 & $\mathrm{D}_{0} \sim \mathrm{D}_{60}$ & $\mathrm{E}_{\mathrm{AC}}, \mathrm{E}_{\mathrm{Ri}}$ & $6-40-40-2$ & 7,500 & 120 & 1.3 \\
\hline 5 & $\mathrm{D}_{0} \sim \mathrm{D}_{60}$ & $\mathrm{E}_{\mathrm{AC}}$ & $6-30-30-1$ & 10,000 & 86 & - \\
\hline 6 & $\mathrm{D}_{0} \sim \mathrm{D}_{60}$ & $\mathrm{E}_{\mathrm{AC}}$ & $6-40-40-1$ & 10,000 & 110 & - \\
\hline 7 & $\mathbf{D}_{0} \sim \mathbf{D}_{60}$ & $\mathbf{E}_{\mathrm{AC}}$ & $6-40-40-1$ & 15,000 & 69 & - \\
\hline 8 & $\mathrm{D}_{0} \sim \mathrm{D}_{60}$ & $\mathrm{E}_{\mathrm{Ri}}$ & $6-30-30-1$ & 10,000 & - & 2.0 \\
\hline 11 & $\mathrm{D}_{0} \sim \mathrm{D}_{60}, \mathrm{BCI}, \mathrm{AI}_{4}$ & $\mathrm{E}_{\mathrm{Ri}}$ & $8-30-30-1$ & 10,000 & - & 1.1 \\
\hline 11 & $\mathrm{D}_{0} \sim \mathrm{D}_{60}, \mathrm{BCI}, \mathrm{AI}_{4}$ & $\mathrm{E}_{\mathrm{Ri}}$ & $8-40-40-1$ & 10,000 & - & 0.9 \\
\hline 12 & $\mathrm{D}_{0} \sim \mathrm{D}_{60}, \mathrm{BCI}, \mathrm{AI}_{4}$ & $\mathbf{E}_{\mathbf{R i}}$ & $8-40-40-1$ & 15,000 & - & 0.8 \\
\hline
\end{tabular}

Table 4. Summary of Sensitivity Analyses for Predicting Base/subbase Moduli Parameters

\begin{tabular}{|c|c|c|c|c|c|c|}
\hline Trial & Input & Output & Network Architecture & No. of Epochs & $\mathbf{n}_{\mathbf{b}}$ & $\mathbf{n}_{\mathrm{s}}$ \\
\hline 2 & $\mathrm{D}_{0} \sim \mathrm{D}_{72}, \mathrm{BCI}, \mathrm{BDI}$ & $\mathrm{n}_{\mathrm{b}}, \mathrm{n}_{\mathrm{s}}$ & $9-40-40-2$ & 15,000 & 0.128 & 0.128 \\
\hline 3 & $\mathrm{D}_{0} \sim \mathrm{D}_{72}, \mathrm{BCI}, \mathrm{BDI}$ & $\mathrm{n}_{\mathrm{b}}$ & $9-40-40-1$ & 10,000 & 0.513 & - \\
\hline 5 & BCI, BDI & $\mathrm{n}_{\mathrm{b}}$ & $2-40-40-1$ & 5,000 & 0.181 & - \\
\hline 6 & $\mathrm{D}_{0} \sim \mathrm{D}_{60}, \mathrm{AUPP}$ & $\mathrm{n}_{\mathrm{b}}$ & $7-20-20-1$ & 15,000 & 0.149 & - \\
\hline 7 & $\mathrm{D}_{0} \sim \mathrm{D}_{60}, \mathrm{AUPP}, \mathrm{E}_{\mathrm{AC}}$ & $\mathrm{n}_{\mathrm{b}}$ & $8-10-1$ & 10,000 & 0.171 & - \\
\hline 8 & $\mathrm{D}_{0} \sim \mathrm{D}_{60}$, AUPP, $\mathrm{E}_{\mathrm{AC}}, \mathrm{D}_{1} / \mathrm{D}_{0}$ & $\mathrm{n}_{\mathrm{b}}$ & $9-10-1$ & 10,000 & 0.130 & - \\
\hline 11 & $\mathrm{D}_{0} \sim \mathrm{D}_{60}, \mathrm{BCI}, \mathrm{BDI}$ & $\mathrm{n}_{\mathrm{s}}$ & $8-40-40-1$ & 5,000 & - & 0.184 \\
\hline 12 & $\mathrm{D}_{0} \sim \mathrm{D}_{60}, \mathrm{BCI}, \mathrm{BDI}$ & $\mathrm{n}_{\mathrm{s}}$ & $8-50-50-1$ & 5,000 & - & 0.489 \\
\hline 13 & $\mathrm{D}_{0} \sim \mathrm{D}_{60}, \mathrm{BCI}, \mathrm{F}_{1}$ & $\mathrm{n}_{\mathrm{s}}$ & $8-40-40-1$ & 10,000 & - & 0.141 \\
\hline 14 & $\mathrm{D}_{0} \sim \mathrm{D}_{60}, \mathrm{E}_{\mathrm{AC}}, \mathrm{E}_{\mathrm{Ri}}$ & $\mathrm{n}_{\mathrm{b}}, \mathrm{n}_{\mathrm{s}}$ & $8-40-40-2$ & 10,000 & 0.130 & 0.135 \\
\hline 15 & $\mathbf{D}_{0} \sim \mathbf{D}_{60}, \mathbf{E}_{\mathrm{AC}}, \mathbf{E}_{\mathrm{Ri}}$ & $\mathbf{n}_{\mathrm{s}}$ & $8-40-40-1$ & 10,000 & - & $\mathbf{0 . 1 3 6}$ \\
\hline
\end{tabular}


backcalculating the base layer modulus, especially if a thin AC layer is used, is a well recognized problem [4]. For this problem, it is sufficient to predict either ' $\mathrm{n}$ ' or ' $\mathrm{k}$ ' for base and subbase layers as both these moduli parameters are related to one another as discussed before. Note that the bestperformance network for predicting $\mathrm{n}_{\mathrm{b}}$ contains ANNpredicted $\mathrm{E}_{\mathrm{AC}}$ as one of the inputs to the network.

The most common inputs for mechanistic analysis of airport flexible pavement performance include:

(1) $\varepsilon_{\mathrm{AC}}$, tensile strain at the bottom of the asphalt layer,

(2) $\varepsilon_{\mathrm{SG}}$, vertical compressive strain on top of the subgrade, and

(3) SSR, Subgrade Stress Ratio defined as follows:

$S S R=\frac{\sigma_{d}}{q_{u}}$

where $\sigma_{d}$ is deviator stress on top of the subgrade and $q_{u}$ is the unconfined compressive strength of subgrade cohesive soils. Distress modes normally considered in flexible pavement analysis and design are fatigue cracking and rutting [10]. Classical flexible pavement design procedures are based on limiting the vertical compressive strain on top of the subgrade (subgrade rutting failure criteria) and the tensile strain at the bottom of the lowest AC layer (AC fatigue failure criteria).
Using the results from ILLI-PAVE finite element analyses, researchers have showed that the SSR is a good indicator of the subgrade condition [11]. The philosophy of the SSR criterion is to ensure that the pavement exhibits stable subgrade permanent deformation performance. The SSR criterion has been successfully utilized in the develop-ment of ILLI-PAVE based flexible highway pave-ment design procedures for the Illinois Department of Trans-portation [12]. The SSR-based subgrade criteria has been proposed for airport flexible pavement design [11].

Using the synthetic deflection basins generated by ILLIPAVE and the derived DBPs, the possibility of developing ANN-based models for predicting $\varepsilon_{\mathrm{AC}}, \varepsilon_{\mathrm{SG}}$, and $\sigma_{\mathrm{d}}$ was explored. Initial analyses showed that predicting these layer condition indicators were extremely difficult. Of the three, $\varepsilon_{\mathrm{AC}}$ was the most difficult to predict. Table 5 summarizes the results of sensitivity analyses in selecting the best-performance networks for predicting $\varepsilon_{\mathrm{AC}}, \varepsilon_{\mathrm{SG}}$, and $\sigma_{\mathrm{d}}$. Based on the magnitude of the testing RMSE for the selected networks (highlighted in the Table), it can be said that the prediction accuracy is reasonable, if not good.

\section{DISCUSSION OF RESULTS}

Table $\mathbf{6}$ displays the summary of all the best-performance ANN-based prediction models identified by the parametric analyses in this study. The training progresses of the bestperformance networks are captured in Figs. 1 to 6.

Table 5. Summary of Sensitivity Analyses for Predicting Pavement Critical Responses

\begin{tabular}{|c|c|c|c|c|c|c|c|}
\hline Trial & Input & Output & Network Architecture & No. of Epochs & $\sigma_{d}(p s i)$ & $\varepsilon_{S G}($ Microstrain $)$ & $\varepsilon_{\mathrm{AC}}$ (Microstrain) \\
\hline 1 & $\mathrm{D}_{0} \sim \mathrm{D}_{5}$ & $\sigma_{\mathrm{d}}$ & $6-20-20-1$ & 5,000 & $9.79 \mathrm{E}-01$ & & \\
\hline 2 & $\mathrm{D}_{0} \sim \mathrm{D}_{5}$ & $\sigma_{\mathrm{d}}$ & $6-20-20-1$ & 20,000 & $9.68 \mathrm{E}-01$ & & \\
\hline 5 & $\mathrm{D}_{0} \sim \mathrm{D}_{5}$ & $\varepsilon_{\mathrm{SG}}$ & $6-40-40-1$ & 5,000 & & 1519 & \\
\hline 6 & $\mathrm{D}_{0} \sim \mathrm{D}_{5}, \mathrm{BDI}$ & $\varepsilon_{\mathrm{SG}}$ & $7-10-10-1$ & 10,000 & & 225 & \\
\hline 7 & $\mathrm{D}_{0} \sim \mathrm{D}_{60}, \mathrm{BDI}$ & $\varepsilon_{\mathrm{SG}}$ & $7-20-20-1$ & 5,000 & & 490 & \\
\hline 8 & $\mathrm{D}_{0} \sim \mathrm{D}_{60}, \mathrm{BDI}$ & $\varepsilon_{\mathrm{SG}}$ & $7-40-40-1$ & 10,000 & & 206 & \\
\hline 7 & $\mathrm{D}_{0} \sim \mathrm{D}_{60}, \mathrm{BDI}, \mathrm{SCI}$ & $\varepsilon_{\mathrm{AC}}$ & $8-15-15-1$ & 10,000 & & & 112 \\
\hline 8 & $\mathrm{D}_{0} \sim \mathrm{D}_{60}, \mathrm{BDI}, \mathrm{SCI}$ & $\varepsilon_{\mathrm{AC}}$ & $8-20-20-1$ & 15,000 & & & 274 \\
\hline 9 & $\mathrm{D}_{0} \sim \mathrm{D}_{60}, \mathrm{BDI}, \mathrm{E}_{\mathrm{AC}}$ & $\varepsilon_{\mathrm{AC}}$ & $8-10-1$ & 10,000 & & & 102 \\
\hline 10 & $\mathbf{D}_{0} \sim \mathbf{D}_{60}, \mathbf{A U P P}, \mathbf{E}_{\mathrm{AC}}$ & $\varepsilon_{\mathrm{AC}}$ & $8-10-1$ & 15,000 & & & 54 \\
\hline 11 & $\mathrm{D}_{0} \sim \mathrm{D}_{60}, \mathrm{AUPP}, \mathrm{E}_{\mathrm{AC}}$ & $\varepsilon_{\mathrm{AC}}$ & $8-10-1$ & 20,000 & & & 81 \\
\hline 12 & $\mathrm{D}_{0} \sim \mathrm{D}_{60}, \mathrm{AUPP}, \mathrm{E}_{\mathrm{AC}}$ & $\varepsilon_{\mathrm{AC}}$ & $8-15-1$ & 10,000 & & & 85 \\
\hline 13 & $\mathrm{D}_{0} \sim \mathrm{D}_{60}, \mathrm{AUPP}, \mathrm{E}_{\mathrm{AC}}$ & $\varepsilon_{\mathrm{AC}}$ & $8-10-10-1$ & 10,000 & & & 92 \\
\hline
\end{tabular}


Table 6. Summary of Best-performance ANN Prediction Models

\begin{tabular}{|c|c|c|c|}
\hline Output & Inputs & Network Architecture & Testing RMSE \\
\hline \hline $\mathrm{E}_{\mathrm{ac}}$ & $\mathrm{D}_{0} \sim \mathrm{D}_{60}$ & $6-40-40-1$ & $69 \mathrm{ksi}$ \\
\hline $\mathrm{E}_{\mathrm{ri}}$ & $\mathrm{D}_{0} \sim \mathrm{D}_{60}, \mathrm{BCI}, \mathrm{AI}_{4}$ & $8-40-40-1$ & $0.8 \mathrm{ksi}$ \\
\hline $\mathrm{n}_{\mathrm{b}}$ & $\mathrm{D}_{0} \sim \mathrm{D}_{60}, \mathrm{AUPP}, \mathrm{E}_{\mathrm{AC}}, \mathrm{D}_{12} / \mathrm{D}_{0}$ & $9-10-1$ & 0.125 \\
\hline $\mathrm{n}_{\mathrm{s}}$ & $\mathrm{D}_{0} \sim \mathrm{D}_{60}, \mathrm{E}_{\mathrm{AC}}, \mathrm{E}_{\mathrm{Ri}}$ & $8-40-40-1$ & 0.136 \\
\hline$\sigma_{\mathrm{d}}$ & $\mathrm{D}_{0} \sim \mathrm{D}_{60}$ & $6-40-40-1$ & $0.947 \mathrm{psi}$ \\
\hline$\varepsilon_{\mathrm{SG}}$ & $\mathrm{D}_{0} \sim \mathrm{D}_{60}$ & $6-20-20-1$ & $0.132 \mathrm{millistrain}$ \\
\hline$\varepsilon_{\mathrm{AC}}$ & $\mathrm{D}_{0} \sim \mathrm{D}_{60}, \mathrm{AUPP}, \mathrm{E}_{\mathrm{AC}}$ & $8-10-1$ & $53.7 \mathrm{microstrain}$ \\
\hline
\end{tabular}

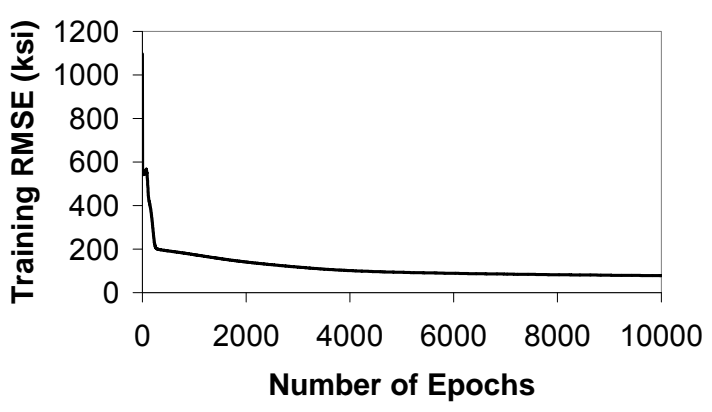

Fig. (1). Training curve for AC modulus.

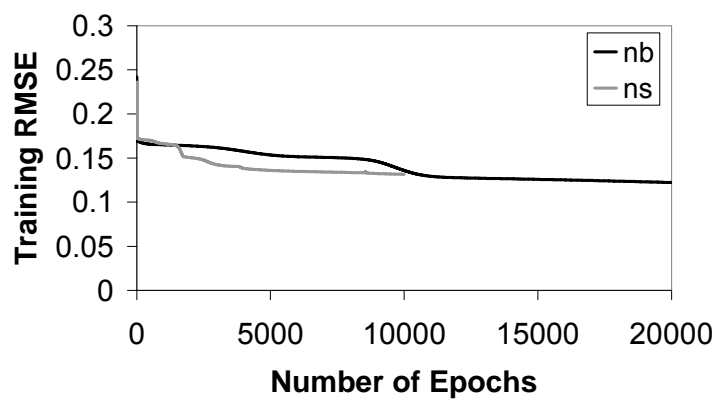

Fig. (2). Training curves for $n_{b}$ and $n_{s}$.

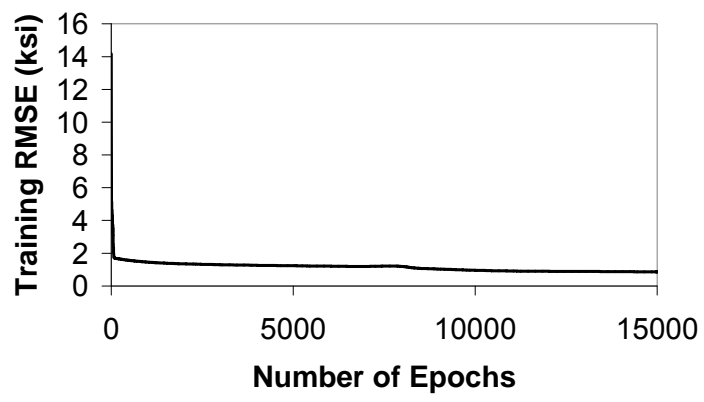

Fig. (3). Training curve for subgrade modulus.

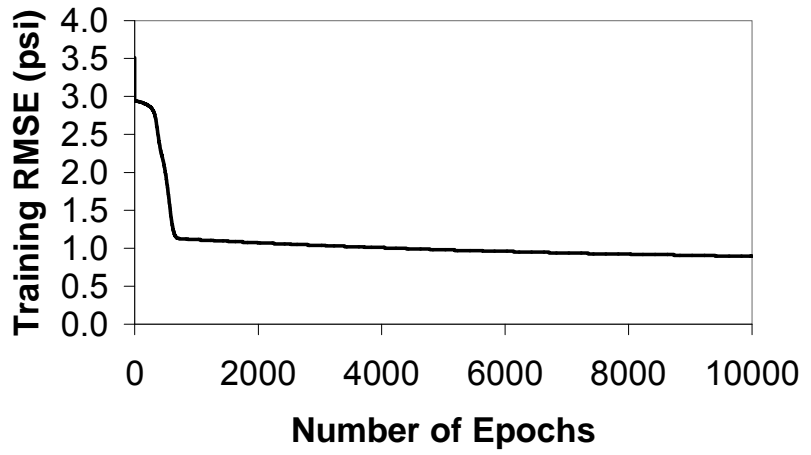

Fig. (4). Training curve for $\sigma_{\mathrm{d}}$.

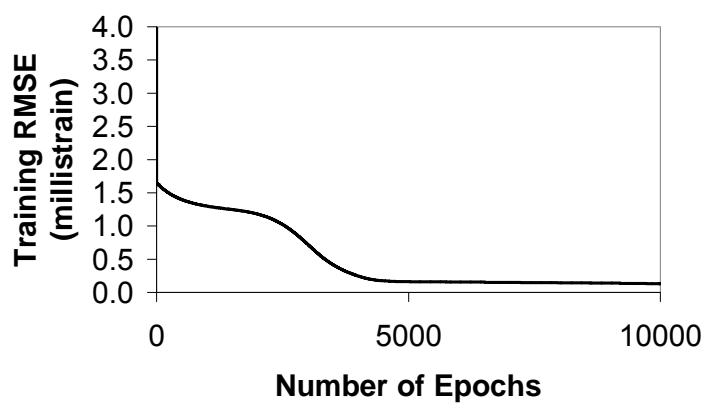

Fig. (5). Training curve for $\varepsilon_{S G}$.

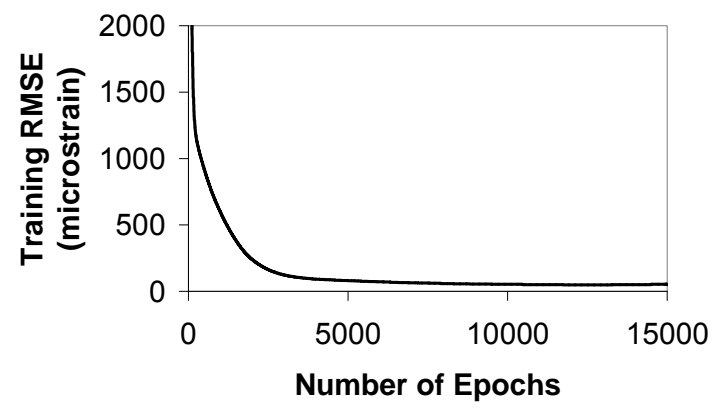

Fig. (6). Training curve for $\varepsilon_{\mathrm{AC}}$. 
In Figs. 7 to 11, the target and ANN-predicted values are compared for all the output variables using the 1,250 test data vectors. Except for base and subbase moduli parameters, very good agreement is found between the target and ANN-predicted values for all output variables. Further research is required to identify the appropriate input variables and the required network architecture to successfully predict the base and subbase moduli parameters.

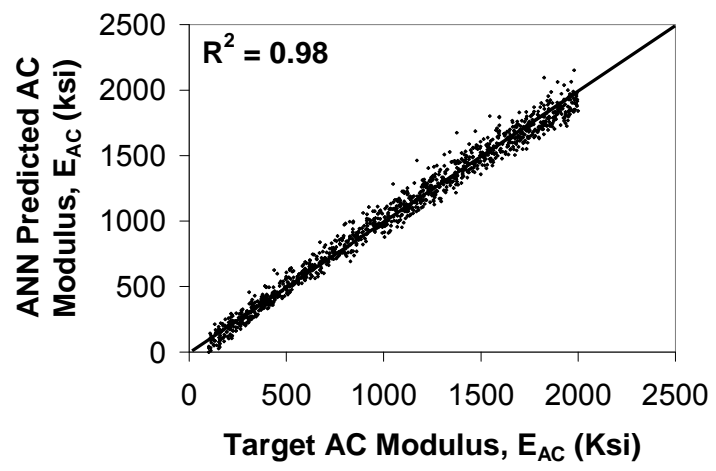

Fig. (7). Prediction of AC modulus.

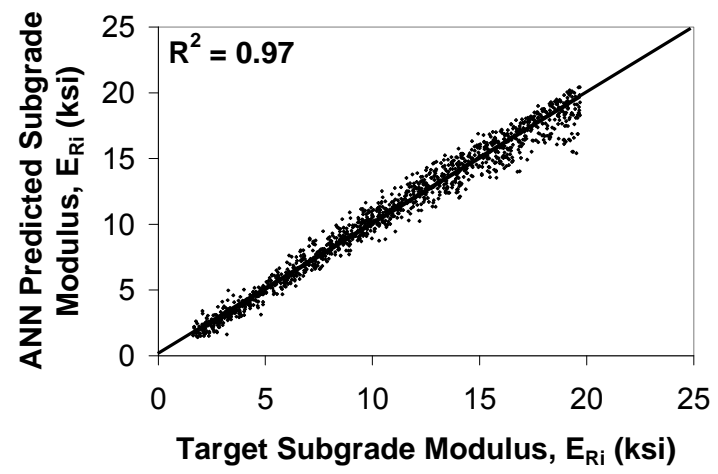

Fig. (8). Prediction of subgrade modulus, $\mathrm{E}_{\mathrm{Ri}}$.

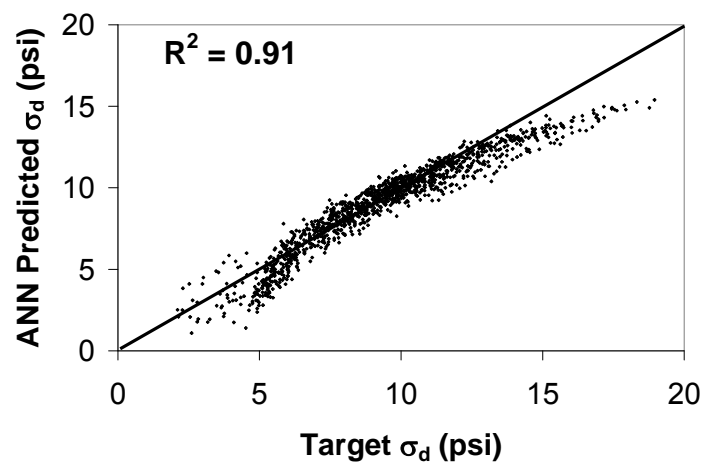

Fig. (9). Prediction of subgrade deviator stress, $\sigma_{\mathrm{d}}$.

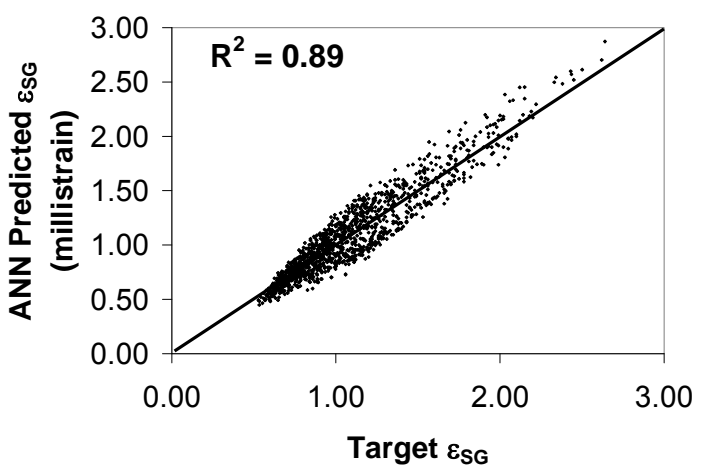

Fig. (10). Prediction of vertical subgrade compressive strain, $\varepsilon_{\mathrm{SG}}$.

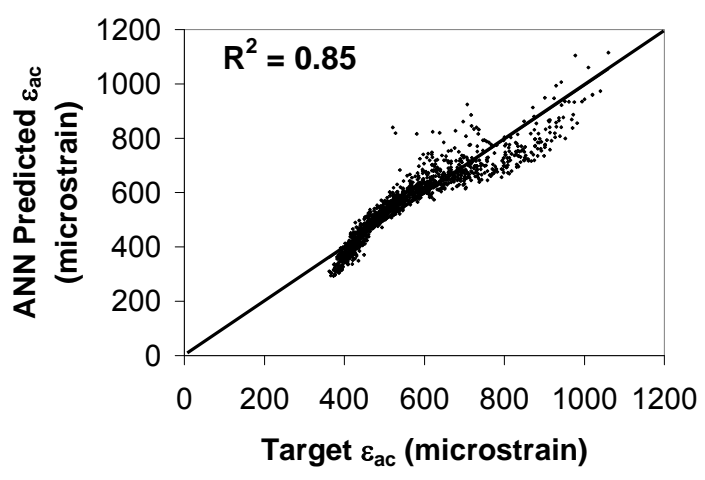

Fig. (11). Prediction of horizontal tensile AC strain, $\varepsilon_{\mathrm{AC}}$.

\section{ANN APPLICATION TO FIELD DATA}

One of the major reasons for developing this backcalculation procedure is to reliably evaluate the structural integrity of the NAPTF pavement test sections as they were subjected to traffic loading. The NAPTF is located at the Federal Aviation Administration (FAA) William J. Hughes Technical Center, Atlantic City International Airport, New Jersey. The NAPTF test pavement area is 900 -foot long and 60-foot wide and it includes six AC pavement sections. One of them is a conventional-base AC pavement built over a medium-strength subgrade which was modeled in this study. This test section is referred to as the "MFC". The test sections were subjected to a six-wheel dual-tridem aircraft landing gear (Boeing 777) in one lane and a four-wheel dualtandem landing gear (Boeing 747) in the other lane simultaneously. The wheel loads were set at 45,000 lbs and the speed was $5 \mathrm{mph}$ during trafficking. The test sections were trafficked to "failure". According to the NAPTF failure criterion, pavements were considered to be failed when there is a 1-inch surface upheaval adjacent to the traffic lane. The MFC test section was the first one to "fail" at 12,952 load repetitions exhibiting 3 to 3.5 inches of rutting and severe cracking. All NAPTF test data referred in this research can be downloaded from the FAA Airport Technology website: http://www.airporttech.tc.faa.gov. 
During the NAPTF traffic test program, HWD tests were conducted at various times to monitor the effect of time and traffic on the structural condition of the pavement. Tests were conducted on B777 traffic lane, B747 traffic lane and the untrafficked Centerline $(\mathrm{C} / \mathrm{L})$. Using the HWD test data acquired at the NAPTF for the MFC test section, the AC moduli and subgrade moduli were backcalculated with the best-performance ANNs. The results were then compared with those obtained using BAKFAA, an ELP-based backcalculation program. The BAKFAA program was developed under the sponsorship of the FAA Airport Technology Branch and is based on the LEAF layered elastic computation program. A stiff layer with a modulus of $1,000,000 \mathrm{psi}$ and a Poisson's ratio of 0.50 was used in backcalculation process. The plots comparing the results of ANN-based approach with those of BAKFAA are shown in Fig. 12 for $\mathrm{AC}$ modulus and in Fig. 13 for subgrade modulus.

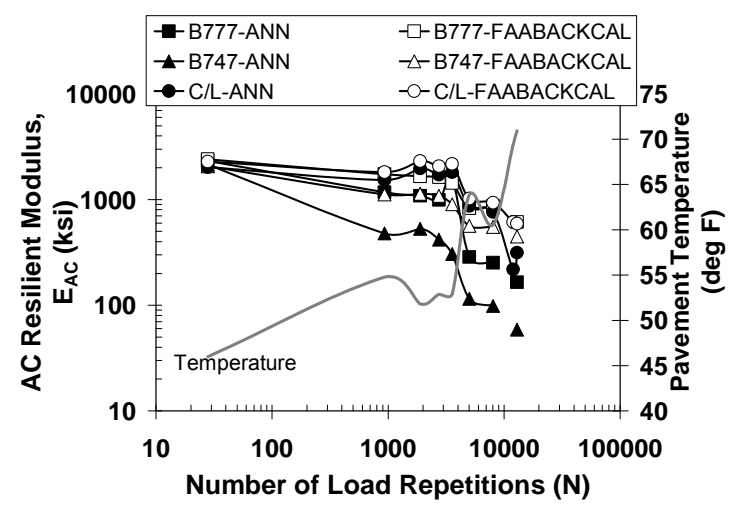

Fig. (12). Comparison of ANN-predicted AC moduli with BAKFAA AC moduli (Field Data).

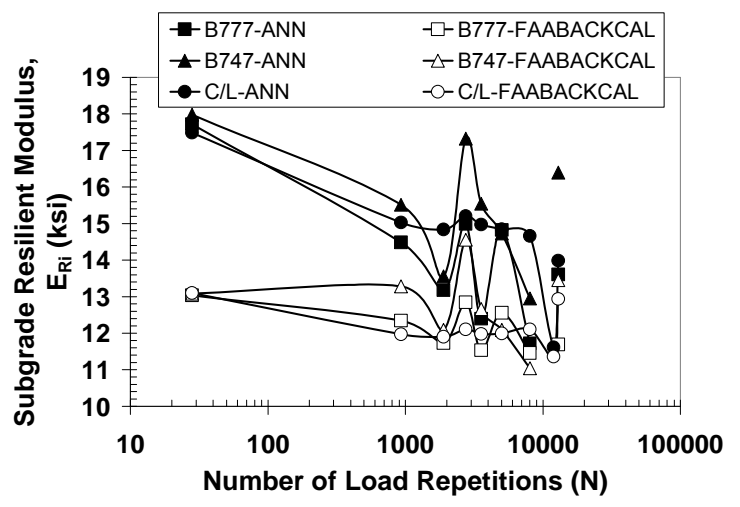

Fig. (13). Comparison of ANN-predicted subgrade moduli with BAKFAA subgrade moduli (Field Data).

In the Figures, "B777-" and "B747-" in the legend refer to B777 traffic lane and B747 traffic lane respectively. One of the objectives of the NAPTF traffic test program was to compare the damaging effect of B777 and B747 landing gears on airport pavements. In these Figures, the changes in layer moduli in B777 traffic lane and B747 traffic lane are due to both traffic loading as well as variation in temperature and climate. The changes in pavement material properties in the pavement Centerline $(\mathrm{C} / \mathrm{L})$ are only due to environmental effects as the $\mathrm{C} / \mathrm{L}$ was not subjected to trafficking.

In Fig. 12, the variation in pavement temperature over the duration of trafficking program is indicated. Studies have shown that the AC modulus is very sensitive to pavement temperature. Therefore, the pavement temperature is plotted as well in Fig. 12 on the secondary $\mathrm{Y}$-axis. The AC modulus Vs $\mathrm{N}$ trend is similar for both ANN-predicted and FAABACKCAL results. The ANN-model seems to be more sensitive to traffic loading effects and temperature effects which is reflected in the sharp decrease in AC moduli with rise in temperature and number of load repetitions. The B747 traffic lane is slightly more distressed in terms of reduction in elastic moduli compared to the B777 traffic lane. This is captured by the ANN-model. This result was confirmed by the NAPTF rutting study results [13]. The NAPTF trench study results showed that the subgrade layer contributed significantly to the total pavement rutting in the MFC test section. The ANN-model shows an overall decreasing trend in subgrade moduli with increasing number of load repetitions, whereas the moduli values backcalculated using BAKFAA remain more or less the same throughout the trafficking program (see Fig. 13).

During the NAPTF construction, 2-inch Pressure Cells (PCs) were installed on top of the subgrade to measure the vertical stresses induced by the test gear during trafficking. Using the 2-inch PC data, vertical subgrade stresses were determined for the B777 traffic lane and B747 traffic lane as a function of the number of load repetitions $(\mathrm{N})$. These values were converted to Subgrade Stress Ratios (SSRs) by dividing the vertical load-induced subgrade stresses by the unconfined compressive strength $\left(\mathrm{Q}_{\mathrm{u}}\right)$ which was determined to be $26.1 \mathrm{psi}$ based on laboratory testing. The vertical loadinduced subgrade stresses were assumed to be approximately equal to the deviator stress on top of subgrade $\left(\sigma_{d}\right)$ in calculating the SSRs. Subgrade deviator stresses $\left(\sigma_{\mathrm{d}}\right)$ were also computed from the HWD deflection basins using the ANN prediction model and were converted to SSRs using the same procedure mentioned above.

The ANN results are compared with the actual PC results in Fig. 14. It is noted that the orders of magnitudes are different for PC results and the ANN results although the trends are similar. This is because the ANN results are based on results from HWD tests which apply a 36,000-lb (36-kip) load on a 12-inch diameter plate on the pavement. Whereas, the PCs measure actual subgrade stresses induced by moving wheel loads of B777 gear (6-wheel) and B747 gear (4-wheel) with 45,000-lb (45-kip) on each wheel. Future research will focus on the feasibility of translating the 36-kip based ANN results to match the actual PC results. However, the ANN results capture the trend in the variation of subgrade stressed with $\mathrm{N}$. The results also confirm that the B747 traffic lane was more distressed compared to the B777 traffic lane as a result of trafficking.

\section{SUMMARY AND CONCLUSIONS}

The Heavy Weight Deflectometer (HWD) test is one of the most widely used tests for assessing the structural 
integrity of airport pavements in a non-destructive manner. In this test, an impulse load is applied to the pavement surface by dropping a weight onto a circular metal plate and the resultant pavement surface deflections are measured directly beneath the plate and at several radial offsets. Backcalculation is the accepted term used to identify a process whereby the elastic (Young's) moduli of individual pavement layers are estimated based upon measured HWD surface deflections. The elastic moduli of the individual pavement layers are effective indicators of layer condition. They are also necessary inputs to mechanistic-based analysis and design of pavements.

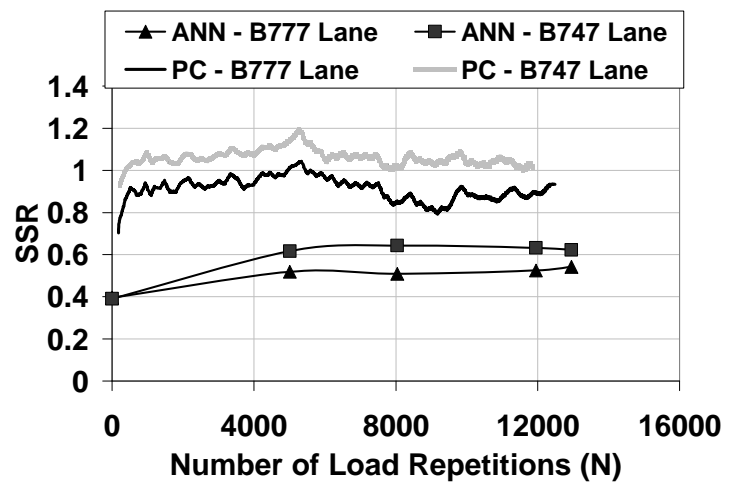

Fig. (14). Comparison of ANN-predicted subgrade stresses with PC-measured subgrade stresses (field data).

The ELP-based backcalculation programs do not account for the stress-dependency of unbound granular materials (used in the base and subbase layers) and fine-grained cohesive soils (used in the subgrade layer) and therefore do not produce realistic results. ILLI-PAVE is a pavement finite-element software that incorporates stress-sensitive material models and it provides a more realistic representation of the pavement structure and its response to loading. The primary objective of this study was to develop a tool for backcalculating non-linear pavement layer moduli from FWD/HWD data using Artificial Neural Networks (ANN). A multi-layer, feed-forward network which uses an errorbackpropagation algorithm was trained to approximate the HWD backcalculation function. The ILLI-PAVE generated synthetic database was used to train the ANN. Using the ANN, we were successfully able to predict the AC moduli and subgrade moduli. Apart from the moduli, the critical pavement responses such as subgrade deviator stress and horizontal AC tensile strain were also successfully predicted using the ANNs. The final product was used in backcalculating pavement layer moduli and in predicting SSRs from actual field data acquired at the National Airport Pavement Test Facility (NAPTF). Although this is a preliminary study with a narrow scope, the results are very encouraging.

Future studies would incorporate a wide range of pavement layer properties in the training dataset which would improve the generalization capabilities of the ANN. They would consider all four (two conventional-base and two asphalt-stabilized base) flexible test sections constructed at the NAPTF. The results would be used in studying the comparative effect of B777 and B747 gears on the moduli values. Further research is required to identify the appropriate input variables and the required network architecture to successfully predict the base and subbase moduli parameters.

\section{ACKNOWLEDGEMENT}

The author gratefully acknowledges Prof. Marshall R. Thompson in guiding the study and Dr. Franco GomezRamirez for generating the ILLI-PAVE synthetic database. Special thanks to Dr. David Brill and Dr. Gordon Hayhoe of FAA Airport Technology Branch for their help in conducting this study. The data referenced in this paper was downloaded from the FAA Airport Technology Branch (NAPTF) Website. The contents of this paper reflect the views of the author who is responsible for the facts and accuracy of the data presented within. The contents do not necessarily reflect the official views and policies of the Federal Aviation Administration. This paper does not constitute a standard, specification, or regulation.

\section{REFERENCES}

[1] G. R. Hicks, "Factors influencing the resilient properties of granular materials", Ph.D. dissertation, University of California, Berkeley, 1970.

[2] M. R. Thompson and Q. L. Robnett, "Resilient properties of subgrade soils", J. Trans. Eng., vol. 105, pp. 71-89, January 1979.

[3] L. Raad and J. L. Figueroa, "Load response of transportation support systems", J. Trans. Eng., vol. 16, pp. 111-128, Janueary 1980.

[4] R. W. Meier and G. J. Rix, "Backcalculation of Flexible Pavement Moduli Using Artificial Neural Networks", in the 73rd Annual Meeting of the Transportation Research Board, 1993.

[5] H. Ceylan, E. Tutumluer, M. Thompson and F. Gomez-Ramirez, "Neural network-based structural models for rapid analysis of flexible pavements with unbound aggregate layers," in 6th International Symposium on Pavements Unbound (UNBAR6), 2004.

[6] G. R. Rada and M.. W. Witczak, "Comprehensive evaluation of laboratory resilient moduli results for granular material", Trans. Res. Rec., vol. 810, pp. 23-33, 1981.

[7] M. Hossain and J. P. Zaniewski, "Characterization of falling weight deflectometer deflection basin”, Trans. Res. Rec., vol. 1293, pp. 1$11,1991$.

[8] B. Xu, R. S. Ranjithan, and R. Y. Kim, "Development of Relationships between FWD Deflections and Asphalt Pavement Layer Condition Indicators", in the 81st Annual Meeting of the Transportation Research Board, 2001.

[9] S. Haykin, Neural Networks: A Comprehensive Foundation. New York: Macmillan College Publishing Company, 1994.

[10] M. R. Thompson and D. Nauman, "Rutting rate analysis of the AASHO road test flexible pavements", Trans. Res. Rec., vol. 1384, pp. 36-48, 1993.

[11] M. Bejarano and M. R. Thompson, "Subgrade soil evaluation for the design of airport Flexible Pavements", FAA-COE Report No. 8 , Department of Civil Engineering, University of Illinois at UrbanaChampaign, Urbana, Illinois, 1999.

[12] M. R. Thompson and R. P. Elliot, "ILLI-PAVE based response algorithms for design of conventional flexible pavements", Trans. Res. Rec., vol. 1043, pp. 50-57, 1985.

[13] K. Gopalakrishnan and M. R. Thompson, "Severity effects of dualtandem and dual-tridem repeated heavier aircraft gear loading on pavement rutting performance", Int. J. Pavement Eng., vol. 7, pp. 179-190, September 2006. 